\title{
Editorial
}

\section{Drivers for Change: Key Global Issues for the Risk Industry}

\author{
Patrick M. Liedtke \\ The Geneva Association, 53 Route de Malagnou, Geneva CH-1208, Switzerland. \\ E-mail: Secretariat@genevaassociation.org
}

The Geneva Papers (2009) 34, 1-8. doi:10.1057/gpp.2008.45

The environment in which the insurance industry operates today is subject to profound changes. In recent years, our industry and the organisational landscape around it have been affected by a series of important developments that, in most cases, will not only continue but will also reinforce themselves. In our opinion, four key drivers for change are the following:

1. Globalisation and market convergence: This trend is effective for the insurance industry and has also triggered the need to cooperate at a new, now global, level and to lead larger debates involving more players with different home markets and diverging strategies but increasingly shared problems. As the industry globalises, so do the bodies that define the frameworks under which it operates. The economic crisis has underlined this point. The most important aspects of this transformational process are:

- the concentration in the insurance industry and the emergence of trans-national companies;

- the tighter relations and integration of worldwide financial markets (the spread of the financial crisis originating in the United States is a prominent example);

- the emergence of similar risks around the globe and the increasing importance to control systematic risk exposures (again, the turmoil in the financial markets is a clear sign of this and more can be expected in the future);

- the appearance of global clients that seek (coherent and streamlined) international solutions to their international problems;

- the closer organisation of nation states in supra-national bodies;

- the creation of more international bodies that project regional and national civil ideas and convictions onto the global level.

2. Regulation goes international: Regulatory and supervisory bodies have started to communicate and coordinate their actions on an international level. The International Association of Insurance Supervisors (IAIS) has gained more traction in recent years and works closely with other financial sector standard-setting bodies and international organisations to promote financial stability. Increasingly it is not national issues that translate into international regulation as similar concerns are discovered elsewhere. In today's global markets, international regulatory efforts tend to start directly at the global level, are coordinated by key stakeholders around the world and are then pushed onto the national level in an attempt to address the issues across national borders. This top-down approach rather than the former bottom-up tradition has changed the dynamics of the system profoundly.

There is a clear need for the world insurance industry also to coordinate its efforts and search for a joint dialogue. Of particular importance are the relations and interaction 
between the industry and the regulatory bodies on an international level. Other parts of the financial services industries already have a tradition of global industry-regulatory dialogue, but for insurance this is a fairly new phenomenon. The Geneva Association has held special meetings with the IAIS and other key international organisations involved in setting regulatory frameworks for the insurance industry for some years now. This includes the recently created annual high-level meeting when the Executive Committee of the IAIS meets with the CEOs from the world's leading insurance companies as represented on The Geneva Association's Board to jointly discuss important developments in the insurance sector and topics affecting insurance regulation and supervision.

3. The increase of the public-private debate: The division of activities between public and private initiatives has been a continuous theme since the emergence of modern society and its economic system. In recent years, questions that directly affect the insurance industry have gained importance. Be it the organisation of the modern welfare state or the insurability of large and/or systematic risks like natural catastrophes or terrorism, the insurance industry has to define its role and find ways for some risk groups to operate alongside or to complement public solutions. Another dimension to the risk-financing process is added by newer financial instruments like securitisation, which now seems to find the traction that it did not have in the past. These new financial instruments extend the range of risk that can be transferred in private markets but require special attention, not least as to how they might affect financial stability in the future.

Discussions as to which classes of risks can be organised efficiently in the marketplace and which ones require (direct or indirect) participation by the state are important to the industry and call for more work on how to tackle these issues credibly and efficiently on an international level.

4. The growing importance of ethical considerations: There is increasing attention as to how large corporations contribute to our societies and their economies. While there have always been laws and rules for the behaviour of agents in a marketplace and what constitutes proper conduct, the quality of these has changed over time. In recent years we have also witnessed the emergence of a discussion about the difference between what is strictly legal and what is perceived to be ethically correct. While firms may be acting without breaking any laws, their actions may not escape the scrutiny of tighter standards set by a, sometimes fuzzy, understanding as to what is appropriate and what is not. Wealthy economies are increasingly less willing to passively accept the decisions made by firms when these inflict damages on society. Special interest groups and customers have started to react not only through their consumptive behaviour but also by taking targeted action against what they perceive as improper conduct within the confines of the law. The fall-out that companies can suffer from ignoring larger ethical issues is considerable, especially for those firms that through the value of their brands have a high public profile. They are also increasingly held responsible for ensuring proper behaviour within their organisations and for enforcing the codes of conduct for all their employees at all times. It is certainly no longer enough to point to the existence of a set of rules and excuse oneself by saying that an employee should have observed these. Companies nowadays are expected to ensure compliance.

More and more communities now regularly try to influence firms in their normal operations from a variety of points of view, questioning their goals, transparency and general code of behaviour. This influence is exerted by means as diverse as legislation, regulation, political activism and pressure through special interest groups. In such a demanding environment, it is natural that firms react by upgrading their working procedures. Consequently, corporate governance, as a key tool to align the interests of all agents within a given organisation with its goals, becomes more relevant and the management (in its best sense) of reputational risk becomes essential. 
At the time this editorial is written, late October 2008, the crisis in the financial markets is in full development. It is a phenomenon that is an outgrowth of the trends above but not a fundamental trend in itself. Without globalisation and the convergence of markets, it would most likely have remained a national phenomenon in the United States without such dire consequences in other parts of the world as we are now witnessing.

Even though already more than a year has passed since the first troubles started back in August 2007, we still cannot say whether the crisis is coming to an end soon. In addition, ever new and unexpected developments linked to the crisis are driving it so quickly that it is difficult to keep up, especially through a medium like The Geneva Papers that has a production lag of about 10-12 weeks. Nevertheless, a number of key questions shall be discussed here in a brief way, even though at this stage of the crisis it is not easy to draw conclusions. This is not only due to the fact that the end of the crisis has not yet fully materialised but also because the impact of the recession in many countries is unknown and further rounds of corrections are possible. What makes the analysis of the consequences of this particular crisis so demanding and complex is the fact that it is composed of three different elements:

- firstly, the original liquidity problems that so much affected the banking sector and which provoked an acute systemic threat;

- secondly, the impact of expected credit losses from subprime mortgages on those financial institutions with specific exposures such as CDSs (credit derivative swaps), MBS (mortgage back securities) and similar; and

- thirdly, the general impact of the asset meltdown which accelerated dramatically since September 2008.

The effects of a world economy in recession are very distinct from the impact that the original credit crisis has had on insurance. While the global credit crisis has already created great problems for some parts of the financial services industry, most insurers have escaped the first two adverse developments (liquidity dry-up and credit losses from subprime mortgages) largely unscathed even though they are major players in the financial markets. This is no small achievement. In 2006, the last full year before the crisis began, the insurance industry had $\$ 18.5$ trillion of assets under management, or 11 per cent of global financial assets. This placed insurers only slightly behind pension funds (\$21.6 trillion) and mutual funds ( $\$ 19.3$ trillion).

While interbank lending for a short time (and until government and central bank action kicked in) came almost to a halt in some regions, like the EU, the insurance industry continued to do business. While banks and many other financial institutions did not trust their peers anymore and hence restricted counterparty interaction to a minimum, the insurance industry continued to share risks on a normal level. We have so far not learned of any major impairment in the ability of insurance companies to obtain reinsurance or problems between reinsurers and their retrocessioners. Whereas many businesses have been complaining over the past weeks that their access to bank liquidity was severely impaired (as has been their access to financial guarantors, including the misleadingly called credit "insurers", i.e. financial guarantors who secure credit positions) and that lending did not take place as they would need it to continue their operations (leading to specific government action in the U.S., Europe and other parts of the world), no wave of complaints as to the functioning of real insurance markets has appeared. Insurance companies and their clients have been able to organise the transfer of risks in an orderly fashion and emergency government action was not needed. This is important to note as it shows how distinct the insurance business is from banking and the provision of other financial services.

In this respect it is important to distinguish three different kinds of financial institutions: banks (retail and investment) on the one hand and (traditional) insurance and reinsurance companies on the other, with a third group, large complex financial institutions, falling in between. While insurers operating in traditional ways have escaped the adverse effects as 
described above, this cannot be said of all large complex financial institutions that conduct insurance. The kind of impact observed at some financial institutions, where the core insurance business was complemented through other financial services activities or where insurance is part of other (mainly banking) financial operations, has been ruinous indeed. Most prominently, AIG and Fortis reported massive losses occurring on financial products (mainly CDS and other financial guarantees) and banking activities and ultimately had to be saved through government intervention. Interestingly enough, their insurance operations have repeatedly been reported as sound by the supervisory authorities whose stringent controls of insurance activities apparently lead to more careful risk management by the insurance operators within those institutions. In the case of AIG, the ability to service the government debts and the losses incurred by the business unit that conducted financial guarantee business depends heavily on the soundness and continued operation of the insurance part of the company.

In short, the main reason for this remarkable resistance of the insurance operators to the first two threats so far has been a combination of the resilience of the insurance business model when it comes to liquidity constraints and prudence by most operators following past experiences. The already tight supervision of insurance operations certainly played a positive role too.

However, this does not mean that insurance companies are able to escape generally negative developments of major asset classes (which are going down in value because of new risk assessment, a deteriorating economic climate and a generally less optimistic growth outlook, rather than just liquidity issues). After all, insurers have large balance sheets and hold a sizeable amount of diverse assets.

If the world economy or some relevant parts of it were to fall into a prolonged and deep recession (rather than a shorter and more limited contraction), then the consequences for insurance and indeed the economy in general could be dire indeed. A protracted and profound recession poses a different set of challenges not only to insurance but also to all economic actors. We can only hold our breath at this time, hoping that the world will escape a major downturn lasting for many quarters. Already the severe asset meltdown that has occurred to date has affected the insurance industry as holder and guardian of important and diverse investments in a very negative way. With every new wave of distress, the solvency positions of more players will be tested. So far they have held up remarkably well.

What is interesting to note, however, is the limited involvement of the insurance sector in the credit crisis itself. The handful of companies that have suffered badly as a consequence of the credit crisis are mostly those that had special operations as financial guarantors. In this sense they did not operate as insurance companies but as owners of and investors in a different type of business. This is where regulators and supervisors will be more alert in the future: insurance companies branching out into risky ventures or other riskier players (such as banks or financial guarantors) moving into insurance, creating possible transmission mechanisms previously unnoticed.

Insurers have not been submitted to the same systemic issues that many banks are facing today. Nor have they contributed to global financial instability. On the contrary, the insurance industry displayed resilience in the face of adverse market conditions (liquidity squeeze) and was in a position to absorb market volatility, thus acting as a stabilising factor at a time of considerable stress in the global financial system. It is important to note that the credit crisis does not question the business model of insurers. There is no shortage of cover for life or nonlife insurance. Capacity appears to be ample and, with the exception of D\&O and E\&O insurance, upward pressure on pricing in most lines of business continues to be modest.

Regardless of how a recession scenario might play out and what other negative developments might still occur, there is one important lesson to be drawn from the credit crisis so far that has not received enough attention, namely that insurers are markedly different from banks and that their distinct business models expose them to lesser risks in the liquidity domain. In fact, the nature of the services rendered by banks and insurers, the underlying, business models and the 
risks associated with them differ considerably. This must be reflected in different regulation and capital requirements for both industries in the future. "Insurers are not banks" is a simple statement but with far-reaching consequences for the economic system and policy-making.

The credit crisis as well as the above-outlined trends raise important questions for the insurance industry on how to react to the challenges and prepare the sector for a future where its role as a key contributor to modern economies will gain in relevance and status. The more relevant and visible the industry becomes, the greater the attention it will receive and the greater the scrutiny it will be placed under.

The insurance industry operates in a demanding environment. It is critical to ensure that this environment evolves in a positive way. This is not only in the interest of the insurance sector itself but in the interest of the general economy. Insuring risks in a modern economy is a multidimensional undertaking. It is a complex business that interacts with many aspects of our lives. The importance of the insurance industry for an economy can only in part be measured by the sheer size of its business, the number of its employees in a given country, the assets under management or its contribution to the national GDP. It actually plays a more fundamental role in the workings of a modern society, being a necessary precondition for many activities that would not take place were it not for insurance. To ensure that this strategic industry is ready for the challenges of the coming decades is not only the task of insurance companies. Governments and public institutions alike have an interest, no, a moral obligation to its citizens to ensure that their risks can be handled in an adequate way. This means that more work has to be done to upgrade educational institutions on all levels, update regulatory frameworks especially on the trans-national level and facilitate the exploration of new solutions to the key question of how to manage risks in a modern economy.

It seems that our world could need a longer-term strategic vision as to the future of insurance, not only from an entrepreneurial point of view but also intellectually and politically. The Geneva Association not only considers such a debate opportune but is backing it proactively. The contributions published in The Geneva Papers on Risk and Insurance - Issues and Practice are one way of helping to create and disseminate the knowledge and understanding needed for this huge task.

$$
* * * * *
$$

This issue of The Geneva Papers on Risk and Insurance - Issues and Practice not only groups several contributions from The Geneva Association's last General Assembly, an event where annually some 50 chief executive officers (CEOs) from the leading insurance companies in the world meet. It also contains a special contribution on Solvency II, one on insurance and postretirement work and three prize-wining papers from our annual Geneva Association/IIS Research Awards, which were presented in Taipei in summer 2008.

Michel Flamée writes about the level playing field in the regulation of financial services. He maintains that during the last few years, the financial industry has been characterised by an ongoing cross-sector and cross-border consolidation of financial institutions spanning banking, securities and insurance institutions and the blurring demarcation of their respective products and instruments. Against the backdrop of these changes, the creation of a level playing field for financial services has become a key challenge for policy makers, regulators and market participants alike. At different national and international levels, regulators and supervisors have been responding to this challenge with a plethora of measures. His paper presents a number of initiatives at different supervisory levels in view of recent financial sector developments and discusses how the challenge of a level playing field is being tackled. While the contribution was written in large part before the latest phase of the economic crisis, it contains a number of thoughts that will be especially of relevance following the turmoil in the financial markets.

The former President of The Geneva Association, Henri de Castries, looks into the key challenges in long-term care coverage for public and private systems. Ageing populations in 
developed countries are being driven by strong social and structural demographic movements leading to a significant growth in the over 65 population. In light of this, long-term care costs will be a major threat to individual assets and public finances over the next 40 years. Existing public schemes covering long-term care exhibit some significant issues, driven by pay-as-you-go designs combined with weak risk definitions. He believes these difficulties will accelerate the need for new financing sources to cover the risks, and he calls for early preparation by both public and private sectors. A new and advantageous public-private partnership has to be invented to meet the ambition of a sustainable and universal coverage. Against this background, key challenges facing the insurers include increasing public awareness of long-term care costs and challenges, risk monitoring and designing innovative and robust solutions for both wealth accumulation and protection products.

The international regulatory environment for the insurance sector is experiencing an intense period of change writes Matthew Elderfield in his contribution on "Solvency II - Setting the Pace for Regulatory Change". The issue of maintaining compliance with international standards has become an increasing priority for insurance regulators worldwide. In recent years the movement toward the global standardisation of insurance regulation has gained momentum, as the industry itself has become more globalised. The significant market turmoil over the past year that has had worldwide impact on the financial sector has added another complex dimension to this environment. His paper argues that there are three key regulatory trends that will impact the insurance industry in the short-to-medium term, based on two underlying key drivers of regulatory change over this time horizon. These drivers can be put simply and should be no surprise. They are: first, Solvency II and second, subprime.

Jacques Aigrain, the current President of The Geneva Association, wonders how to square the circle between accounting and solvency. His article makes a clear case for economic valuation. Whether it is companies' internal models, rating agencies, regulators or standard-setting organisations, differing stakeholder views on the required and available capital are converging towards economic and risk-based capital and valuation models. He maintains that economic valuation will help foster innovation and advance the search for the most efficient risk transfer mechanisms, regardless of their form. Solvency II not only contains a clear commitment to economic valuation, it also effectively addresses some key issues highlighted by the current financial market crisis. He therefore draws the conclusion that it should be implemented in the European Union without delay. He furthermore argues that full credit should be given for diversification effects on a global scale, which will strengthen the motivation to actively manage portfolio diversification and will encourage stronger risk management.

Denis Duverne and Jacques LeDouit discuss the key issues and reflect on the current debates around two important regulatory projects: Solvency II and International Financial Reporting Standards (IFRS) Phase II. According to their analysis, the Solvency II project is based on an economic balance sheet and proposes an economic valuation of insurance liabilities that is very close to the European industry position on assessment of risks and solvency requirements based on how the business is managed. One key element is still under debate: diversification across portfolios. The industry considers that the entity's own diversification must be reflected in the valuation of the insurance liabilities while the Committee of European Insurance and Occupational Pensions Supervisors has referred to an empty undertaking. The authors explain that IFRS Phase II can appear to be an approach similar to Solvency II but actually is based on fundamental flaws, excluding future cash flows and insurers' actions, referring to a theoretical market participant efficiency instead of the entity's specific data for expenses, unbundling artificially insurance and financial components, taking into account insurer's own credit standing and adding a service margin to the risk margin. The diverging timetables of IFRS and Solvency II lead to a risk that IFRS and Solvency could be non-aligned and increase the danger that IFRS for insurance could be distant from the economics of the business. A consensus within 
the industry is therefore crucial to facilitate the progress of the international standard for insurance accounting that would give a true and fair presentation of the economics of the business.

In a paper not based on a contribution from our General Assembly, but submitted as an original article on the issues surrounding Solvency II, Ines Holzmüller looks at RBC Standards in the United States, Solvency II and the Swiss Solvency Test, comparing the three. She describes a conceptual framework introduced by David Cummins in 1994 for policy makers to use in analysing risk-based capital systems. Based on the framework, this article provides an overview and critical analysis of risk-based capital requirements, with a focus on property/casualty insurance, as implemented in three regions of the world: the United States, the European Union and Switzerland. To integrate the dynamics of the insurance and capital markets and recent developments in regulation, she adds four new criteria to the original framework. The analysis reveals various shortcomings of the standards used in the United States and indicates a need for reform in that country. In contrast, the Swiss standards and the framework planned for the European Union perform generally well when benchmarked against the criteria. In the view of the author, it is, however, not yet possible to identify which of these two systems is superior, as empirical evidence on their effectiveness in protecting policyholders is still lacking.

The China Insurance Regulatory Commission is strengthening its supervision of agricultural business and exploring a set of regulations for this sector, as explained by Zhou Yanli. The importance of agriculture in a country with 1.3 billion people is, according to the paper, selfevident. Agricultural insurance, however, did not emerge in China until the 1930s. Having gone through twists and turns, agricultural insurance is now widely recognised in China as an important means of protection for production and for the life of people in rural areas. Under the guidance and with the support of the government at all levels, pilot projects of agricultural insurance are being carried out. As a result, the market is growing quickly; the market structure has become more diversified and more products are available. Zhou Yanli describes how, using pilot efforts to find a good model for agricultural insurance in China, some successful experiments have been made. The paper concludes that policy support is found to be a necessity in a sustainable agricultural insurance system for China. Local differences should receive appropriate attention and innovation should be encouraged to create a practical agricultural system that satisfies local needs in a large country like China.

In their award-winning paper, Wei Zheng and his co-authors provide a comparative study of international insurance markets. By proposing the Benchmark Ratio of Insurance Penetration as a new paradigm for international insurance comparison, their article makes a new assessment and comparison of insurance growth levels of certain countries as well as certain economic groups, and further discusses the policy implications. The main conclusions of the paper are as follows. First, it is necessary to have a new recognition of the international insurance growth pattern: the relative level of insurance growth in developed markets has declined as compared with that indicated by traditional indicators and the relative level of insurance growth in developing markets has increased. The relative growth level of the insurance industry in developed markets is still higher than that in developing markets, but the insurance industry in emerging markets and Brazil, Russia, India and China (BRIC) is undergoing rapid development and has achieved a relatively high level. Second, when considering global expansion strategy, insurance companies should not only continue to consolidate market share in developed markets, but also actively explore developing markets. In the meantime, insurance companies need to pay special attention to the fact that the relative insurance growth of emerging markets and BRIC has already reached a relatively high level. Although there is still significant potential for growth, the authors believe that the growth will mainly be driven by the normal economic factors and the pattern of insurance growth would be expected to experience great changes. Third, the insurance industry policy for developing countries should focus on the adjustment 
and improvement of the pattern of growth instead of the quantitative increase in growth, in order to build a solid foundation for sustainable insurance growth in the long-term future. Fourth, the traditional paradigms are confined by certain limitations, so that we have to establish a more solid paradigm for international insurance comparison. By doing so, the authors are convinced that a more reasonable foundation for international cooperation in insurance regulation and for relevant negotiation of international trade can be built.

In the second award-winning paper in this issue of The Geneva Papers, Etti Baranoff and Thomas Sager explore the U.S. life insurers' exposure to Mortgage-Backed Securities (MBS) and its potential impact on capital should the credit ratings of these bonds be lowered. They analyse 2 years: 2003 (well before the realisation of problems with these instruments) and 2006 (immediately prior). They create five potential scenarios of different severity for recategorising MBS credit ratings and compute the theoretical impact on measured insurer asset risk, via a proxy for the $\mathrm{C}-1$ component of life insurers' risk-based capital. Under all scenarios the authors find large increases in assessed asset risk. They then model insurer capital structure as a function of asset risk and other factors to assess whether insurers had prepared their capital structures for the possibility of problems with these instruments. The findings indicate not only that insurers were unprepared for MBS downgrades, but also that they reduced capital as they accumulated MBS, as though acquiring MBS should raise the overall quality of the investment portfolio. Finally, the authors analyse possible adjustments to capital to accommodate the now recognised increased risks of MBS. Their models suggest, for example, that an insurer with median residential MBS exposure might be expected to increase its capital by 10 per cent or more to maintain a historical relationship between capital and risk factors, in the event of a moderate recategorisation of MBS risk.

In Gustavo Ferro's award-winning paper on the life insurance market's response to ageing, the reaction of the life insurance industry to ageing and the next massive de-accumulation phase of pension funds worldwide is described. According to the author, the industry has a wellestablished product, which is the annuity, a unique instrument to cope with longevity risk, but annuity markets remain thin. Demand-side and supply-side elements of the market are explored, and also regulatory issues. Some proposals are made for a more proactive involvement of the industry in the pension business, by addressing demand-side, supply-side and regulatory concerns. The author's proposal is a multi-tier insurance package that combines different insurance products in order to cover longevity risk as well as bequest or long-term care motives.

Our joint paper on Silver Workers, which is based on a research project conducted by Jürgen Deller and his research team in cooperation with The Geneva Association, looks at old-age security and post-retirement activities of a special group of persons - Silver Workers. We maintain that as a result of the demographic development, there is an increasing understanding of the lack of sustainability of the existing pension schemes. Moreover, agencies are forecasting an intensified lack of specialised staff that will noticeably affect the growth of many developed economies in the foreseeable future. The explorative paper focuses on the present empirical situation and expectations of paid and voluntarily active retirees - the so-called Silver Workers. Germany was selected as the object of the research because it was not only the first country to introduce comprehensive social security schemes, but it is also a typical case for many other developed economies with low fertility rates. In the paper, the need to change the policy regarding Silver Workers is discussed. The lifestyles of the elderly as well as reasons for engagement in post-retirement activities and necessary framework conditions of work during retirement are described. In addition, the qualitative and quantitative survey allows us to derive practical recommendations for leadership, human resource management and policies as well as for the insurance industry. We estimate that integrating Silver Workers can contribute to macroeconomic growth potential, relieve old-age pension systems ("Fourth Pillar"), provide new business opportunities and increase individual life satisfaction. 